\title{
How to manage new oral anticoagulants in case of surgery
}

\author{
Davide Imberti
}

AUSL Piacenza, Italy

\begin{abstract}
When a patient receiving new oral anticoagulants (NOACs) requires an invasive procedure, the consequences of bleeding if anticoagulation is continued and the risk of thrombosis if it is omitted need to be carefully considered. In addition to the bleeding risk of the procedure, it is of paramount importance to evaluate the renal function, especially for dabigatran that is eliminated predominantly via the renal pathway. NOAC therapy should be stopped for at least $24 \mathrm{~h}$ before the intervention, and a longer interruption should be considered in cases of high bleeding risk procedures and/or renal failure. A base-line assessment of coagulation should be performed and intervention should be postponed (if possible) if high levels of anticoagulation parameters are found. In the post-surgical period, if oral anticoagulant therapy cannot be re-started, patients should temporarily receive low molecular weight heparins and re-start NOACs as soon as possible.
\end{abstract}

\section{Background}

The number of patients receiving anticoagulants is increasing year by year and this currently involves millions of people worldwide. Therefore, it is not surprising that many of these patients need invasive or surgical procedures. In fact, it has been estimated that around one in 10 patients taking anticoagulants for cardioembolic prevention in non-valvular atrial fibrillation and mechanical heart diseases or prevention of venous thromboembolism recurrence, require surgery each year. ${ }^{1}$ In the RELY study, approximately $25 \%$ of patients assigned to both doses of dabigatran and warfarin needed invasive surgical procedures. ${ }^{2}$

The peri-procedural period represents a condition at high bleeding risk, requiring discontinuation of anticoagulants but this period is in any case at high risk of embolic complications due to discontinuation of antithrombotic drugs. ${ }^{3}$ The balance between bleeding and

Correspondence: Davide Imberti, AUSL Piacenza, Italy.

E-mail: D.Imberti@ausl.pc.it

Key words: new oral anticoagulants, low molecular weight heparins, surgery, bleeding risk, thrombosis.

Received for publication: 18 March 2013.

Revision received: 10 July 2013.

Accepted for publication: 2 August 2013.

This work is licensed under a Creative Commons Attribution NonCommercial 3.0 License (CC BY-NC 3.0).

(C) Copyright D. Imberti, 2013

Licensee PAGEPress, Italy

Italian Journal of Medicine 2013; 7(s8):36-40

doi:10.4081/itjm.2013.s8.36 embolic risk is of the utmost importance for driving the optimal management of anticoagulation in the peri-operative setting. Anticoagulants should be stopped in high bleeding risk procedures; this means $2-4 \%$ of major bleeds rate within $48 \mathrm{~h}$ of surgery, while low bleeding risk procedures $(0-2 \%$ within $48 \mathrm{~h})$ also represent a cause for concern (Table 1). ${ }^{4}$ When interruption of therapy is indicated, the practical recommendations for vitamin $\mathrm{K}$ antagonists in the peri-operative setting suggest their discontinuation five days before surgery and their resumption 24-48 $\mathrm{h}$ after surgery if adequate hemostasis has been achieved. ${ }^{3}$ Together with the bleeding risk secondary to procedures, the individual bleeding risk should also be assessed (Table 2). ${ }^{5}$ On the other hand, the individual and procedural embolic risk should be closely evaluated. Within the thromboembolic diseases represented by mechanical valve diseases, atrial fibrillation and venous thromboembolism, it is possible to stratify patients in high-, moderate- and low-risk patients for embolic complications after drug discontinuation (Table 3). ${ }^{3}$ For highrisk patients in whom the embolic risk overcomes the bleeding risk, the bridging therapy with low molecular weight heparins (LMWH) in anticoagulant doses is strongly recommended. ${ }^{3} \mathrm{LMWH}$ at anticoagulant dosage should be started five days before procedure, discontinued $24 \mathrm{~h}$ before from surgery and resumed 12-24 $\mathrm{h}$ after the procedure. ${ }^{3}$ However, a recently published metaanalysis seems to demonstrate that the bridging therapy is associated with higher bleeding risk without advantages in reducing the embolic risk. ${ }^{6}$

\section{How to manage NOACs in the peri-operative settings}

To date, there is little solid literature evidence on real world patients receiving new oral anticoagulants 
(NOACs) and surgery. In the RE-LY study, the bleeding risk in the peri-procedural period was similar between both doses of dabigatran $(110 \mathrm{mg} /$ bid and 150 $\mathrm{mg} / \mathrm{bid}$ ) and warfarin, but the median time of drug discontinuation before the invasive procedures was significantly shorter in dabigatran patients (median 2 days) compared to the group treated with warfarin (median 5 days). ${ }^{2}$

Despite this lack of evidence, practical recommendations for management of NOACs in the peri-procedural setting have been indicated..$^{7-10}$ In patients treated with NOACs and requiring invasive procedures, it is first necessary to clearly identify the level of urgency of the intervention (election, urgency, emergency) and subsequently to consider the following issues:
- the thrombotic and hemorrhagic risk of the procedure and of the patient;

- the NOAC half-life [which is shorter than vitamin $\mathrm{K}$ antagonists (VKAs)] in patients with normal and impaired renal function;

- the onset of anticoagulation effect of NOACs (which is usually within $2 \mathrm{~h}$ provided that intestinal absorption is normal);

- the dose and the timing of the last intake of the drug;

- the possibility of pharmacological reversal of anticoagulation in case of emergency procedures. ${ }^{7-12}$

\section{Elective surgery}

If patients require an invasive procedure or surgical intervention, NOAC therapy should be discontinued (ide-

Table 1. Procedural bleeding risk.

High risk (48-h bleeding rate $2-4 \%$ )

- Heart valve replacement

- Coronary-artery by-pass

- Abdominal aortic aneurismal repairment

- Neurosurgical, urological, head and neck, abdominal and breast cancer surgery

- Bilateral knee replacement

- Laminectomy

- Transurethral prostate resection

- Kidney biopsy

- Polypectomy, variceal treatment, biliary sphincterectomy, pneumatic dilatation

- $\quad$ PEG placement

- Endoscopically guided aspiration

- Multiple tooth extrcation

- Vascular and general surgery

- Any surgical intervention lasting $>45$

Low risk (48-h bleeding rate $0-2 \%$ )

- All other surgical procedures

Adapted from Spyropoulos and Douketis, $2012 .^{4}$

Table 2. Individual bleeding risk.

- Active bleeding

- Acquired bleeding disorders

- Concomitant use of anticoagulants

- Lumbar puncture or epidural or spinal anesthesia to be performed within the next $12 \mathrm{~h}$ or performed in the last $4 \mathrm{~h}$

- Acute ischemic or hemorrhagic stroke

- Platelet count $<75 \times 10^{9} / \mathrm{L}$

- Uncontrolled systolic hypertension

- Untreated inherited bleeding disorders 
ally for at least $24 \mathrm{~h}$ before the intervention) and restarted when adequate hemostasis has been re-established. This applies to patients who are scheduled to undergo surgery. However, if emergency surgery is needed, no further NOAC tablets should be taken and, if possible, surgery should be delayed until the half-life of the NOACs has elapsed. In this scenario, the prothrombin time test with the use of a rivaroxaban-sensitive reagent (such as Néoplastine CI Plus) (for rivaroxaban) or a chromogenic anti-Factor Xa assay (for rivaroxaban and apixaban) or an activated partial thromboplastin partial time/diluted thrombin time (dTT, Hemoclot) assay (for dabigatran) should be used to measure anticoagulant activity in plasma. Persistently high levels of anticoagulation parameters are suggestive of high plasmatic levels of NOACs and the intervention, if possible, should be postponed. If the procedure cannot be delayed, the treating physician should assess the increased risk of bleeding against the urgency of the intervention. After the intervention, NOACs should be re-started as soon as possible (however, at least $12 \mathrm{~h}$ after the end of the procedure), provided that the clinical situation allows, and that adequate hemostasis has been established; moreover, according to the thrombotic and bleeding risk and to the type of procedure, re-starting with a lower dose of NOACs is advisable (for example $10 \mathrm{mg}$ /day for rivaroxaban, half a daily dose for dabigatran and apixaban). It is worthy of note that, owing to the fast onset of action of NOACs, it is not necessary for patients to receive bridging therapy with parenteral unfractionated heparin or LMWH after the procedure. When oral treatment cannot be administered immediately after surgery, patients should re-start anticoagulant therapy with LMWH and re-introduce NOACs as soon as possible..$^{7-10}$

\section{Emergency procedures/surgery}

In emergency surgery for non-bleeding patient, every attempt should be made to delay surgery, at least for $24 \mathrm{~h}$. If the intervention or the procedure (e.g. emergency coronary angioplasty, or a diagnostic endoscopic procedure) is at low bleeding risk, NOAC administration should be continued. If bleeding risk is increased it is recommended to assess the presence and entity of anticoagulant activity by the abovementioned laboratory tests. If residual anticoagulant activity is detected, the use of non-activated prothrombin complex concentrates (PCCs) or activated PCCs (FEIBA) should be considered for the urgent reversal of patients treated with dabigatran and PCCs for rivaroxaban ${ }^{4}$ when the procedure cannot be postponed and the risk of bleeding is very high. When surgery cannot be delayed, or in patients requiring surgical approach to stop bleeding, the urgent reversal of NOACs should be performed..$^{7-10}$

The peri-operative management of patients treated with NOACs is summarized in Table 4.

\section{How to manage anesthesia in patients receiving NOACs}

In the surgical setting, the optimal management of antithrombotic drugs according to the kind of anesthesia is fundamental. While there are no particular recommendations for general anesthesia other than those abovementioned for DOACs withdrawal, neuraxial anesthesia requires close attention in patients taking antithrombotic drugs due to bleeding risk in the phases of insertion and removal of epidural catheter. ${ }^{13}$ Epidural catheter can be inserted or removed only after a period of time corresponding to the sum of two half-lives plus the time needed to reach the plasma peak concentration. Moreover, after catheter insertion or removal, the antithrombotic drug can be administered after a time corresponding to the clot formation which is around $8 \mathrm{~h}$ less the time to reach the peak plasma concentration (Table 5). ${ }^{13,14}$

Table 3. The assessment of embolic risk.

\begin{tabular}{|c|c|c|c|}
\hline Risk & Mechanical heart valve & Atrial fibrillation & Venous thromboembolism \\
\hline High & $\begin{array}{l}\text { Mechanical mitral valves } \\
\text { Old aortic valves } \\
\text { TIA/stroke within } 6 \text { months }\end{array}$ & $\mathrm{CHADS}_{2}$ score 5-6 & $\begin{array}{l}\text { Deep vein thrombosis or } \\
\text { pulmonary embolism within } 3 \text { months } \\
\text { Severe thrombophilia }\end{array}$ \\
\hline Intermediate & $\begin{array}{l}\text { Bileaflet aortic valve plus at } \\
\text { least one of: atrial fibrillation, } \\
\text { previous TIA/stroke, blood } \\
\text { hypertension, diabetes, heart } \\
\text { failure or age }>75 \text { years }\end{array}$ & $\mathrm{CHADS}_{2}$ score 3-4 & $\begin{array}{c}\text { Deep vein thrombosis or } \\
\text { pulmonary embolism within 3-12 months } \\
\text { Recurrent VTE } \\
\text { Non severe thrombophilia } \\
\text { Active cancer }\end{array}$ \\
\hline Low & Bileaflet aortic valve only & $\begin{array}{l}\mathrm{CHADS}_{2} \text { score } 0-2 \text { and no } \\
\text { previous TIA/stroke }\end{array}$ & $\begin{array}{l}\text { Deep vein thrombosis or } \\
\text { pulmonary embolism over } 12 \text { months }\end{array}$ \\
\hline
\end{tabular}

TIA, transient ischemic attack; VTE, venous thromboembolism. Adapted from Douketis et al., 2012.3 


\section{How to switch from NOACs to other anticoagulants and vice versa}

Both in the surgical setting and in other situations, the switch between VKAs or LMWHs or unfractionated heparin and NOACs or vice versa could be necessary. The practical recommendations for the switching between VKAs and NOACs suggest to start dabigatran when the international normalized ratio (INR) values are less than 2.0 and rivaroxaban when INR are less than 3.0, and conversely, the VKAs should be started from three days before to the day before the NOACs withdrawal based on $\mathrm{CrCl}^{7,8}$ In patients with normal $\mathrm{CrCl}$, VKAs can be assumed from three days between discontinuation of DAOC, while patients with moderate renal impairment, VKAs should be assumed the day before the NOACS withdrawal. ${ }^{7,8}$ The NOACs may be administered at the appointed time of LMWHs and vice versa LMWHs can be administered at the appointed time of NOACs when it is decided to switch from one to another therapy. ${ }^{7,8,15}$ The NOACs may be administered $2 \mathrm{~h}$ after discontinuation of intravenous unfractionated heparin and intravenous unfractionated heparin can be started at the time of the planned dose of the NOACs. ${ }^{7,8,15}$

\section{Conclusions}

In conclusion, peri-operative management of NOACs seems to be simpler and easier than of warfarin for several reasons, i.e. shorter half-life, faster offset and onset of action, no need for bridging therapy with LMWHs. Of course, these considerations should be confirmed in large scale, well-designed clinical trials.

Table 4. Interruption of apixaban, dabigatran and rivaroxaban before elective surgery or invasive procedures.

\begin{tabular}{|c|c|c|c|}
\hline \multirow[t]{2}{*}{ Calculated creatinine clearance, $\mathrm{mL} / \mathrm{min}$} & \multirow[t]{2}{*}{ Half-life (h) } & \multicolumn{2}{|c|}{ Timing of last dose before surgery } \\
\hline & & Standard risk of bleeding* & High risk of bleeding ${ }^{\circ}$ \\
\hline Apixaban & $12(9-14)$ & $24 \mathrm{~h}$ & $48 \mathrm{~h}^{\#}$ \\
\hline \multicolumn{4}{|l|}{ Dabigatran } \\
\hline$>80$ & $13(11-22)$ & $24 \mathrm{~h}$ & $2 \mathrm{~d}$ \\
\hline$>50$ and $</=80$ & $15(12-34)$ & $24 \mathrm{~h}$ & $2 \mathrm{~d}$ \\
\hline$>30$ and $</=50$ & $18(13-23)$ & $2 \mathrm{~d}$ & $4 \mathrm{~d}$ \\
\hline$</=30$ & $27(2-35)$ & $4 \mathrm{~d}$ & $6 \mathrm{~d}$ \\
\hline \multicolumn{4}{|l|}{ Rivaroxaban } \\
\hline$>30$ & $12(11-13)$ & $24 \mathrm{~h}$ & $2 \mathrm{~d}$ \\
\hline$<30$ & Unknown & $2 \mathrm{~d}$ & $4 \mathrm{~d}$ \\
\hline
\end{tabular}

*e.g. cardiac catheterization, ablation therapy, colonscopy without removal of large polyps, and uncomplicated laparoscopic procedures (such as cholecystectomy). ${ }^{\circ}$ e.g. cardiac surgery, insertion of pacemakers or defibrillators (resulting from the risk for pocket hematoma), neurosurgery, large hernia surgery and major cancer/urological/vascular surgery; "includes also moderate risk of bleeding. Modified from Douketis et al., 2012. ${ }^{3}$

Table 5. Neuroaxial anesthesia in patients receiving anticoagulants.

\begin{tabular}{lcccc}
\hline & $\begin{array}{c}\text { Time from last drug } \\
\text { administration and } \\
\text { catheter insertion }\end{array}$ & $\begin{array}{c}\text { Time from catheter } \\
\text { insertion and } \\
\text { new drug administration }\end{array}$ & $\begin{array}{c}\text { Time from last drug } \\
\text { administration and } \\
\text { catheter removal }\end{array}$ & $\begin{array}{c}\text { Time between } \\
\text { catheter removal and } \\
\text { new drug administration }\end{array}$ \\
\hline UFH & $\begin{array}{c}4 \mathrm{~h} \\
\text { (aPTT dependent) }\end{array}$ & $\begin{array}{c}1 \mathrm{~h} \\
\text { (aPTT dependent) }\end{array}$ & $\begin{array}{c}1 \mathrm{~h} \\
\text { (aPTT dependent) }\end{array}$ & $\begin{array}{c}1 \mathrm{~h} \\
\text { (aPTT dependent) }\end{array}$ \\
\hline LMWH & $12 \mathrm{~h}$ & $6-8 \mathrm{~h}$ & $12 \mathrm{~h}$ & $6 \mathrm{~h}$ \\
\hline Fondaparinux & $24-36 \mathrm{~h}$ & $6-12 \mathrm{~h}$ & $36 \mathrm{~h}$ & $6-12 \mathrm{~h}$ \\
\hline VKAs & $\mathrm{INR}<1.5$ & $\mathrm{INR}<1.5$ & INR $<1.5$ & INR $<1.5$ \\
\hline Dabigatran & Data not available & Data not available & Data not available & $6 \mathrm{~h}$ \\
\hline Rivaroxaban & $18 \mathrm{~h}$ & $6 \mathrm{~h}$ & $18 \mathrm{~h}$ & $6 \mathrm{~h}$ \\
\hline Apixaban & $26-30 \mathrm{~h}$ & $4-6 \mathrm{~h}$ & $26-30 \mathrm{~h}$ & $4-6 \mathrm{~h}$ \\
\hline
\end{tabular}

UFH, unfractionated heparin; aPTT, activated partial thromboplastin time; LMWH, low molecular weight heparins; VKAs, vitamin K antagonists; INR, international normalized ratio. 


\section{References}

1. Baron TH, Kamath PS, McBane RD. Management of antithrombotic therapy in patiemnts undergoing invasive procedures. N Eng J Med 2013;368:2113-24.

2. Healey JS, Eikelboom J, Douketis J, et al. Periprocedural bleeding and thromboembolic events with dabigatran compared with warfarin: results from the Randomized Evaluation of Long-Term Anticoagulation Therapy (RE-LY) Randomized Trial. Circulation 2012; 126:343-8.

3. Douketis JD, Spyropoulos AC, Spencer FA, et al. Perioperative management of antithrombotic therapy: Antithrombotic Therapy and Prevention of Thrombosis, $9^{\text {th }}$ Ed: American College of Chest Physicians EvidenceBased Clinical Practice Guidelines. Chest 2012;141: e326S-50S.

4. Spyropoulos C, Douketis JD. How I treat anticoagulated patients undergoing an elective procedure or surgery. Blood 2012;120:2954-62.

5. National Institute for Health and Clinical Excellence CG92. Venous thromboembolism - reducing the risk: NICE guidelines. Available from: www.nice.org.uk/ guidance/CG92

6. Siegal D, Yudin J, Kaatz S, et al. Periprocedural heparin bridging in patients receiving vitamin $\mathrm{K}$ antagonists: systematic review and meta-analysis of bleeding and thromboembolic rates. Circulation 2012; 126:1630-9.

7. Huiman MV, Lip GY, Diener HC, et al. Dabigatran etex- ilate for stroke prevention in patients with atrial fibrillation: resolving uncertainties in routine practice. Thromb Haemost 2012;107:838-47.

8. Turpie AGG, Kreutz R, Llau J, et al. Management consensus guidance for the use of rivaroxaban -an oral, direct factor Xa inhibitor. Thromb Haemost 2012;108: 876-86.

9. Palareti G, Ageno W, Ferrari A, et al. Clinical management of rivaroxaban-treated patients. Expert Opin Pharmacother 2013. [Epub ahead of print].

10. Heidbuchel H, Verhamme P, Alings M, et al. EHRA Practical Guide on the use of new oral anticoagulants in patients with non-valvular atrial fibrillation: executive summary. Eur Heart J 2013. [Epub ahead of print].

11. Eerenberg ES, Kamphuisen PW, Sijpkens MK, et al. Reversal of rivaroxaban and dabigatran by prothrombin complex concentrate: a randomized, placebo-controlled, crossover study in healthy subjects. Circulation 2011; 124:1573-9.

12. Siegal DM, Crowther MA. Acute management of bleeding in patients on novel oral anticoagulants. Eur Heart J 2013;34:489-500.

13. Green L, Machin SJ. Managing anticoagulated patients during neuraxial anaesthesia. Br J Haematol 2010;149: 195-208.

14. Gogarten W, Vandermeulen E, Van Aken H, et al. Regional anaesthesia and antithrombotic agents: recommendations of the European Society of Anaesthesiology. Eur J Anaesthesiol 2010;27:999-1015.

15. Schulman S, Crowther MA. How I treat with anticoagulants in 2012: new and old anticoagulants, and when and how to switch. Blood 2012;119:3016-23. 